\title{
Pharmacological Basis for the Medicinal Use of Lepidium sativum in Airways Disorders
}

\author{
Najeeb-ur Rehman, ${ }^{1,2}$ Arif-ullah Khan, ${ }^{3}$ Khalid M. Alkharfy, ${ }^{4}$ and Anwarul-Hassan Gilani ${ }^{1,4}$ \\ ${ }^{1}$ Natural Product Research Unit, Department of Biological and Biomedical Sciences, The Aga Khan University Medical College, \\ Karachi 74800, Pakistan \\ ${ }^{2}$ Department of Pharmacology, Faculty of Pharmacy, University of Karachi, Karachi 75270, Pakistan \\ ${ }^{3}$ Institute of Pharmaceutical Sciences, Kohat University of Science and Technology, Kohat 26000, Pakistan \\ ${ }^{4}$ Department of Clinical Pharmacy, College of Pharmacy, King Saud University, Riyadh 11451, Saudi Arabia
}

Correspondence should be addressed to Anwarul-Hassan Gilani, anwar.gilani@aku.edu

Received 6 September 2011; Accepted 10 October 2011

Academic Editor: Raffaele Capasso

Copyright (C) 2012 Najeeb-ur Rehman et al. This is an open access article distributed under the Creative Commons Attribution License, which permits unrestricted use, distribution, and reproduction in any medium, provided the original work is properly cited.

\begin{abstract}
Lepidium sativum is widely used in folk medicine for treatment of hyperactive airways disorders, such as asthma, bronchitis and cough. The crude extract of Lepidium sativum (Ls.Cr) inhibited carbachol (CCh, $1 \mu \mathrm{M}-)$ and $\mathrm{K}^{+}(80 \mathrm{mM}-)$ induced contractions in a pattern similar to that of dicyclomine. Ls.Cr at $0.03 \mathrm{mg} / \mathrm{mL}$ produced a rightward parallel shift of CCh curves, followed by nonparallel shift at higher concentration $(0.1 \mathrm{mg} / \mathrm{mL})$, suppressing maximum response, similar to that caused by dicyclomine. Pretreatment of tissues with Ls.Cr $(0.1-0.3 \mathrm{mg} / \mathrm{mL})$ shifted $\mathrm{Ca}^{++}$concentration-response curves (CRCs) to right, as produced by verapamil. Ls.Cr at low concentrations $(0.03-0.1 \mathrm{mg} / \mathrm{mL})$ caused leftward shift of isoprenaline-induced inhibitory CRCs, like that caused by rolipram, a phosphodiesterase (PDE) inhibitor. These results indicate that bronchodilatory effect of Lepidium sativum is mediated through a combination of anticholinergic, $\mathrm{Ca}^{++}$antagonist and PDE inhibitory pathways, which provides sound mechanistic background for its medicinal use in the overactive airways disorders.
\end{abstract}

\section{Introduction}

Most of the disorders of respiratory system results from the hyperactivity of airways. Asthma is a major congestive respiratory disorder, characterized by episodic wheezing, cough, and chest tightness, associated with airflow obstruction. The worldwide prevalence of asthma has been increasing particularly in children. According to the World Health Organization, it affects about $5-10 \%$ of adults and $10 \%$ of children globally [1]. Cough is a spasmodic contraction of the thoracic cavity that results in abrupt release of air from the lungs. Excessive cough is one of the most common symptoms for which the patients seek medical care and may represent up to one-third of a pulmonologist's outpatient practice referrals [2].

The conventional therapy for these congestive airways disorders particularly asthma is not always safe, efficacious and is beyond the access and/or affordability of large proportion of world population, who look for alternative therapeutic measures. Phytotherapy is the most popular alternative remedy, and a number of traditional systems of medicine are heavily based on the use of herbs as medicine [3, 4]. At the same time, there is a global revival of interest in the use of botanicals, and the physicians of the modern medicine are now beginning to accept the traditional remedies once they are scientifically validated $[5,6]$.

Lepidium sativum Linn. belongs to family Cruciferae (cabbage family) and is commonly known as "Common cress," "Garden cress," or "Halim." The plant is called "Hab el Rashaad" or "Thufa" in Saudi Arabia and is a popular herbal plant grown in many regions of Saudi Arabia, such as Hijaz, AL-Qaseem, and the Eastern Province $[7,8]$. In Europe and America, the leaves are used in salad. In various countries of Africa, Lepidium sativum seeds are thought to be an effective medicinal remedy to cure respiratory disorders, like bronchitis and asthma [9]. The plant is cultivated as 
culinary vegetable all over Asia [10]. In South Asia, it is used in traditional medicine to treat asthma, bronchitis, and cough and is considered useful as abortifacient, antibacterial, aphrodisiac, diuretic, expectorant, gastrointestinal stimulant, gastroprotective, laxative, and stomachic $[11,12]$.

The plant is known to contain imidazole, lepidine, semilepidinoside A and B [13], $\beta$-carotenes, ascorbic acid, linoleic acid, oleic acid, palmitic acid, stearic acid [14], sinapic acid and sinapin [15]. Lepidium sativum is reported to exhibit antihypertensive [16], diuretic [17], antiinflammatory, analgesic, anticoagulant [18], antirheumatic [19], hypoglycemic [20], laxative, prokinetic [21], antidiarrheal, and antispasmodic [22] properties. It has been shown to possess antiasthmatic [23] and bronchodilatory [24] potential in preliminary studies, but there is no report available in the literature on the pharmacological basis for its medicinal use in airways disorders. In this study, we explored the possible mechanisms underlying its airways relaxant effect, mediated through multiple pathways, including inhibitory effect on muscarinic receptors, $\mathrm{Ca}^{++}$channels and phosphodiesterase (PDE) enzyme; thus, this study provides sound pharmacological rational for its effectiveness in the airways hyperactive disorders.

\section{Materials and Methods}

2.1. Plant Material and Extraction. Seeds of Lepidium sativum were purchased from herbal store (Bin Menqash, Riyadh, Saudi Arabia) in March, 2010. The plant was authenticated by Dr. Mohammed Yusuf, King Saud University, and the specimen has been preserved at the herbarium of the College of Pharmacy, King Saud University, Riyadh, Saudi Arabia and also at Natural Product Research Unit, Department of Biological and Biomedical Sciences, Aga Khan University, Karachi with voucher no. Ls-SE-04-10-98. The Lepidium sativum seeds were soaked in $70 \%$ methanol for three days [25] and then filtered through muslin cloth and Whatman filter paper (Maidstone, UK). This procedure was repeated three times, and all the filtrates were pooled and evaporated on rotary evaporator (model RE-111, Buchi, Flawil, Switzerland) under reduced pressure $(-760 \mathrm{~mm} \mathrm{Hg})$ to obtain the crude extract of Lepidium sativum (Ls.Cr), yielding approximatly $15 \%$.

2.2. Chemicals and Animals. Atropine sulphate, carbachol (CCh), dicyclomine, isoprenaline, verapamil, and rolipram were purchased from Sigma Chemicals Company, St. Louis, MO, USA. Guinea-pigs (500-550 g) of either sex and local breed were kept at the Animal House of the Aga Khan University, maintained at $23-25^{\circ} \mathrm{C}$, and were given standard diet and tap water. Experiments were performed in compliance with the rulings of the Institute of Laboratory Animal Resources, Commission on Life Sciences, National Research Council [26] and approved by Ethical Committee of the Aga Khan University.

2.3. Guinea-Pig Trachea. Tracheal ring strips obtained from guinea-pigs sacrificed by cervical dislocation were mounted individually in $20 \mathrm{~mL}$ tissue bath containing Kreb's solution, at $37^{\circ} \mathrm{C}$ and aerated with carbogen. A tension of $1 \mathrm{~g}$ was applied to each of the tissues and equilibrated for $1 \mathrm{hr}$ before the addition of any drug. Carbachol $(1 \mu \mathrm{M})$ and $\mathrm{K}^{+} 0020(80 \mathrm{mM})$ were used to induce sustained contractions, and relaxant activity of crude extract was assessed by adding in cumulative fashion. High $\mathrm{K}^{+}(>30 \mathrm{mM})$ is known to cause smooth muscle contractions through opening of voltage-dependent L-type $\mathrm{Ca}^{++}$channels, thus allowing influx of extracellular $\mathrm{Ca}^{++}$causing a contractile effect and the substance causing inhibition of high $\mathrm{K}^{+}$-induced contraction is considered as inhibitor of $\mathrm{Ca}^{++}$influx $[27,28]$. The antimuscarinic effect of plant extract was investigated through constructing CCh-concentration-response curves (CRCs) in its presence [29]. The $\mathrm{Ca}^{++}$channel blockade (CCB) effect of test substance was confirmed via building $\mathrm{Ca}^{++}$-CRCs in the $\mathrm{Ca}^{++}$free medium [28]. The presence of PDE inhibitory effect was evaluated indirectly through constructing isoprenalineinduced inhibitory CRCs against CCh-induced contractions in absence and presence of plant material, as described previously [30]. Isometric responses were recorded on a Grass model 7 Polygraph (Grass Instrument Company, Quincy, MA, USA).

2.4. Statistical Analysis. The median effective concentrations $\left(\mathrm{EC}_{50}\right)$ with $95 \%$ confidence intervals (CIs) are provided. CRCs were analyzed by nonlinear regression using GraphPad program (GraphPAD, San Diego, CA, USA).

\section{Results}

3.1. Inhibitory Effect of Ls.Cr on CCh and High $\mathrm{K}^{+}$-Induced Contractions. When tested against CCh $(1 \mu \mathrm{M}-)$ and $\mathrm{K}^{+}$ (80 mM-) induced contractions, Ls.Cr inhibited the CChinduced contractions at lower concentration with $\mathrm{EC}_{50}$ value of $0.32 \mathrm{mg} / \mathrm{mL}(0.30-0.44,95 \% \mathrm{CI})$, compared to its effect against $\mathrm{K}^{+}(80 \mathrm{mM})$ with $\mathrm{EC}_{50}$ value of $5.4 \mathrm{mg} / \mathrm{mL}$ (4.3-7.2) as shown in Figure 1(a). Dicyclomine also showed a similar pattern of inhibitory effect (Figure $1(\mathrm{~b})$ ) with respective $\mathrm{EC}_{50}$ values of $0.28 \mu \mathrm{M}(0.20-0.40)$ and $4.6 \mu \mathrm{M}(3.0-7.2)$, whereas verapamil was more potent against $\mathrm{K}^{+}$-induced contractions with $\mathrm{EC}_{50}$ value of $0.14 \mu \mathrm{M}(0.10-0.20)$, when compared with CCh-induced contractions $(2.7 \mu \mathrm{M}$ (1.73.5)) as shown in Figure 1(c). Atropine only relaxed the CCh $(1 \mu \mathrm{M}-)$ induced contraction, with $\mathrm{EC}_{50}$ value of $0.006 \mu \mathrm{M}$ (0.002-0.01), without any effect on $\mathrm{K}^{+}(80 \mathrm{mM}-)$ induced contractions (Figure $1(\mathrm{~d})$ ), as expected.

3.2. Effect of Ls.Cr on CCh Curves. Pretreatment of the tissues with Ls.Cr at $0.03 \mathrm{mg} / \mathrm{mL}$ caused rightward parallel shift of CCh curves, without suppression of maximum contractile response, followed by a non-parallel shift with the suppression of maximum response at next higher concentration, $0.1 \mathrm{mg} / \mathrm{mL}$ (Figure 2(a)). Dicyclomine (0.03-0.1 $\mu \mathrm{M}$ ) also showed a similar pattern of shift (Figure 2(b)), while verapamil $(0.1-0.3 \mu \mathrm{M})$ produced a nonparallel rightward shift at both tested concentration with suppression of the maximum response (Figure $2(\mathrm{c}))$. Atropine $(0.01-0.03 \mu \mathrm{M})$ 


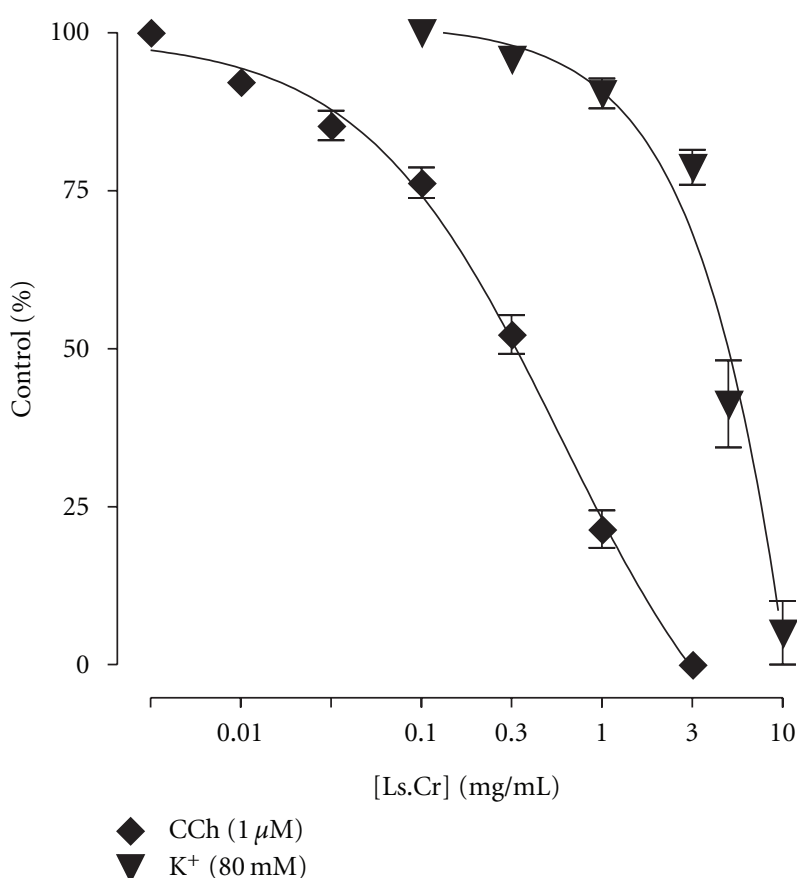

(a)

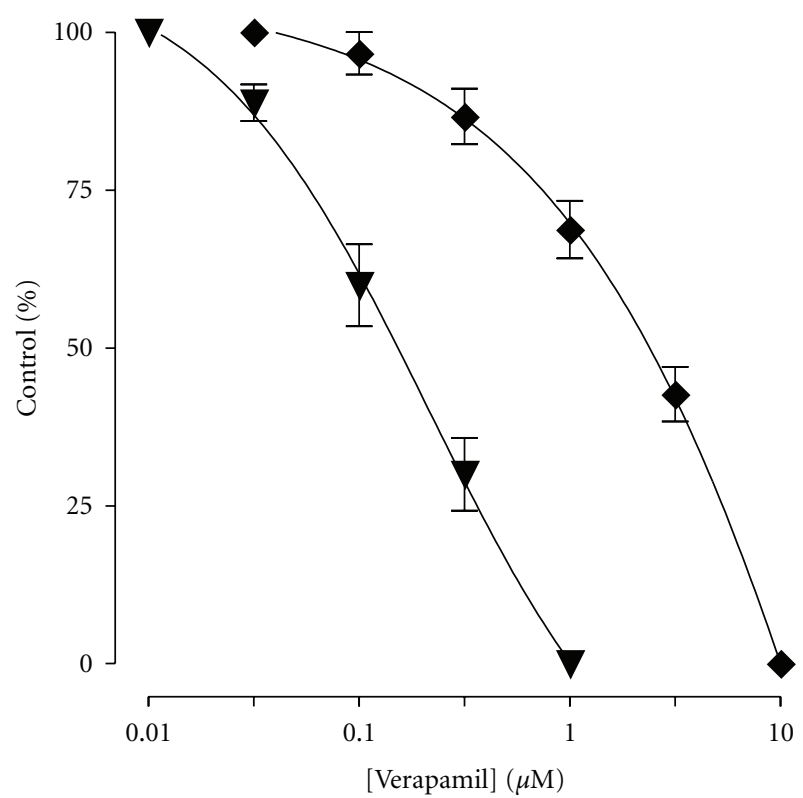

$\operatorname{CCh}(1 \mu \mathrm{M})$

$\nabla \mathrm{K}^{+}(80 \mathrm{mM})$

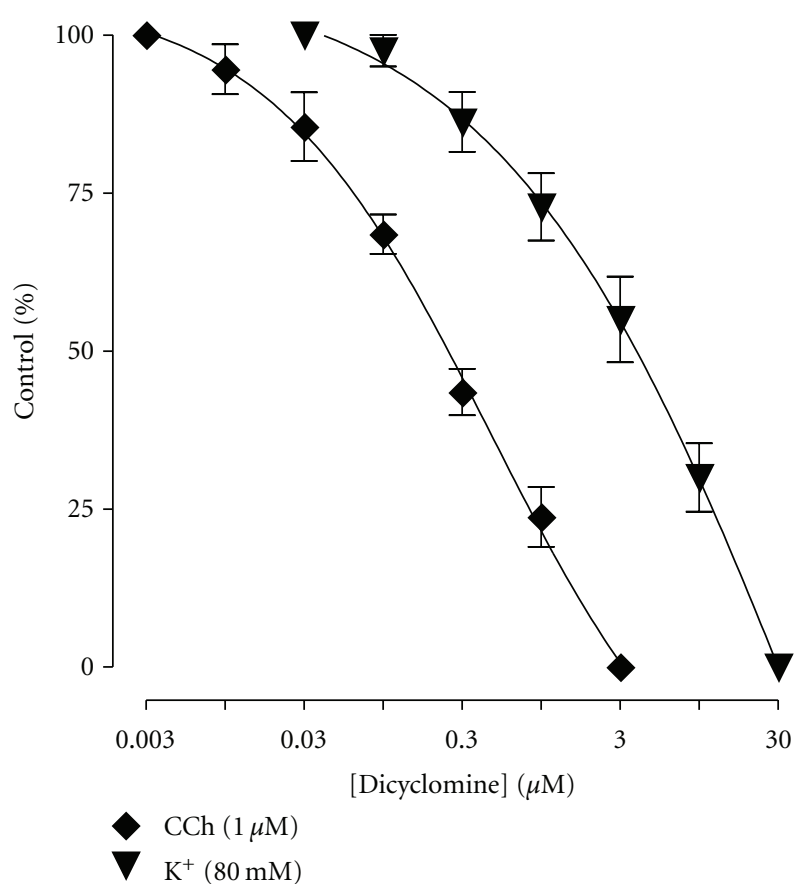

(b)

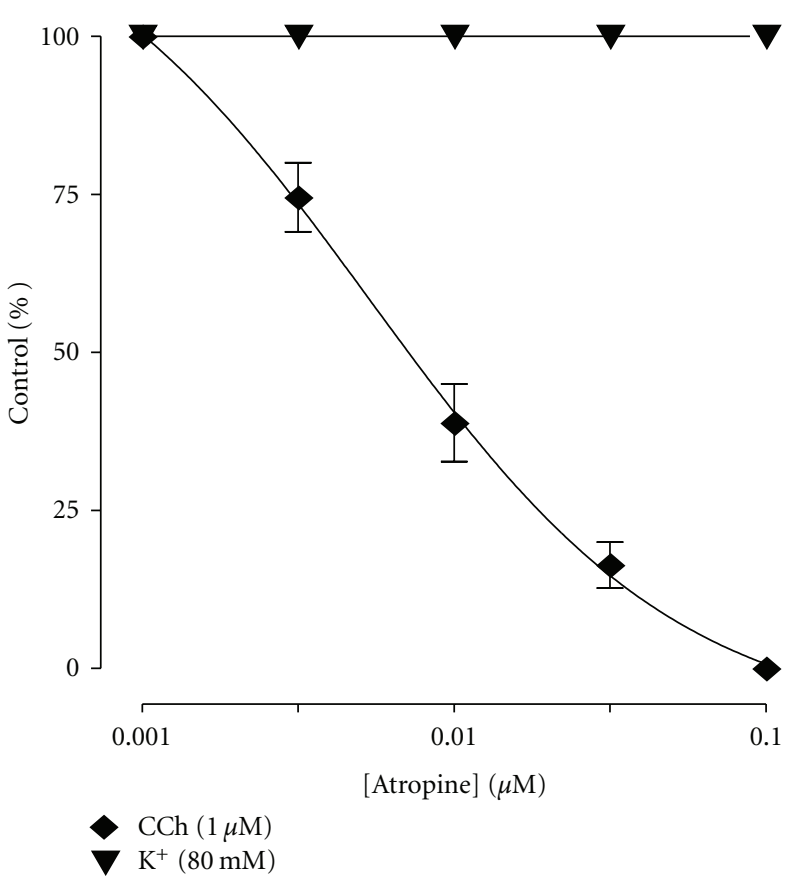

(d)

Figure 1: Concentration-response curves showing comparison (a) crude extract of Lepidium sativum (Ls.Cr), (b) dicyclomine, (c) verapamil, and $(\mathrm{d})$ atropine for the inhibitory effect against carbachol $(\mathrm{CCh})$ and high $\mathrm{K}^{+}$-induced contractions in isolated guinea-pig tracheal preparations, $n=3-5$.

caused rightward parallel shift without the suppression of the maximum contractile effect (Figure 2(d)).

3.3. Effect of Ls.Cr on $\mathrm{Ca}^{++}$Curves. When tested for the possible interaction with $\mathrm{Ca}^{++}$channels, Ls.Cr $(0.1-0.3 \mathrm{mg} / \mathrm{mL})$ produced rightward shift in the $\mathrm{Ca}^{++}$curves (Figure 3(a)), similar to that caused by verapamil (Figure 3(b)).
3.4. Effect of Ls.Cr on Isoprenaline Curves. Pretreatment of tissues with Ls.Cr at low concentrations $(0.03-0.1 \mathrm{mg} / \mathrm{mL})$ shifted the isoprenaline-induced inhibitory CRCs to the left (Figure 4(a)), showing potentiating effect. Rolipram (0.3$1.0 \mu \mathrm{M}$ ) also caused similar leftward shift of the isoprenaline curves, as shown in Figure 4(b). Dicyclomine, verapamil, and atropine were found devoid of such effect (data not shown). 


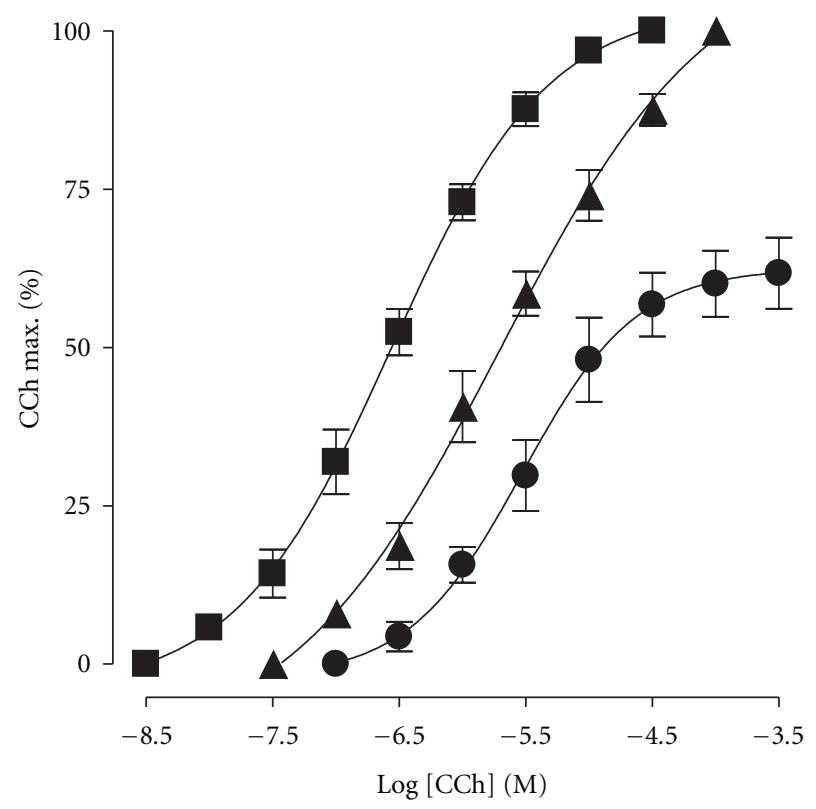

Control

A $\operatorname{Ls.Cr}(0.03 \mathrm{mg} / \mathrm{mL})$

Ls.Cr $(0.1 \mathrm{mg} / \mathrm{mL})$

(a)

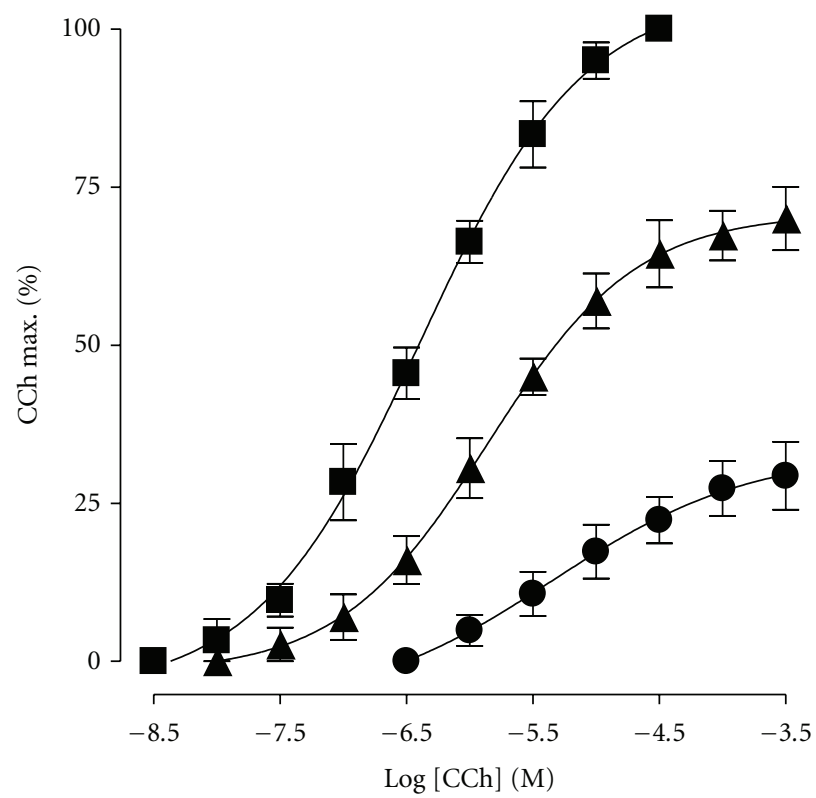

Control

- Verapamil $(0.1 \mu \mathrm{M})$

Verapamil $(0.3 \mu \mathrm{M})$

(c)

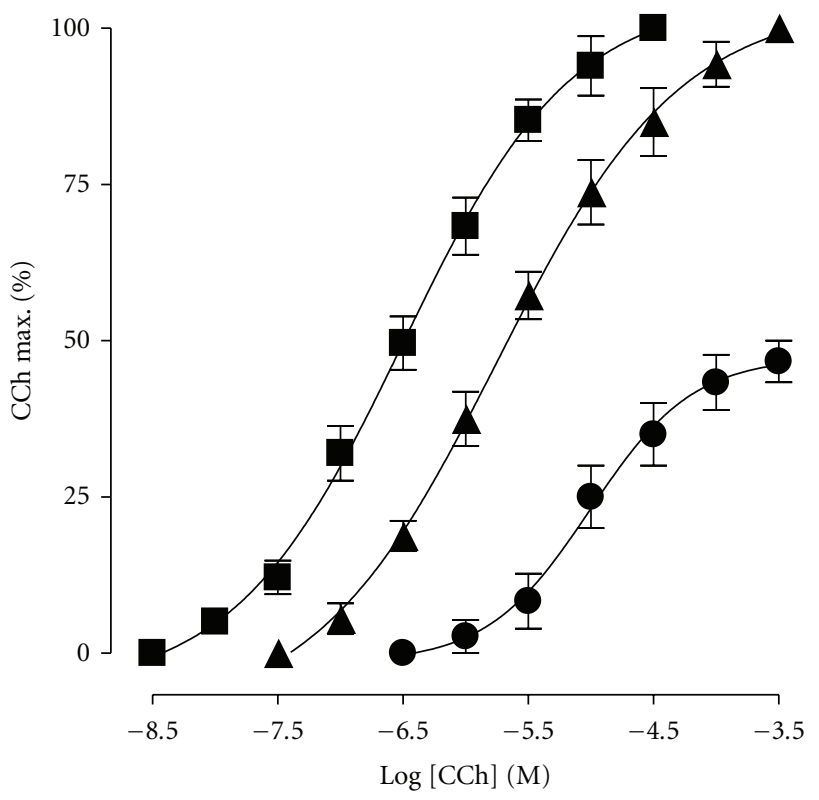

Control

A Dicyclomine $(0.03 \mu \mathrm{M})$

Dicyclomine $(0.1 \mu \mathrm{M})$

(b)

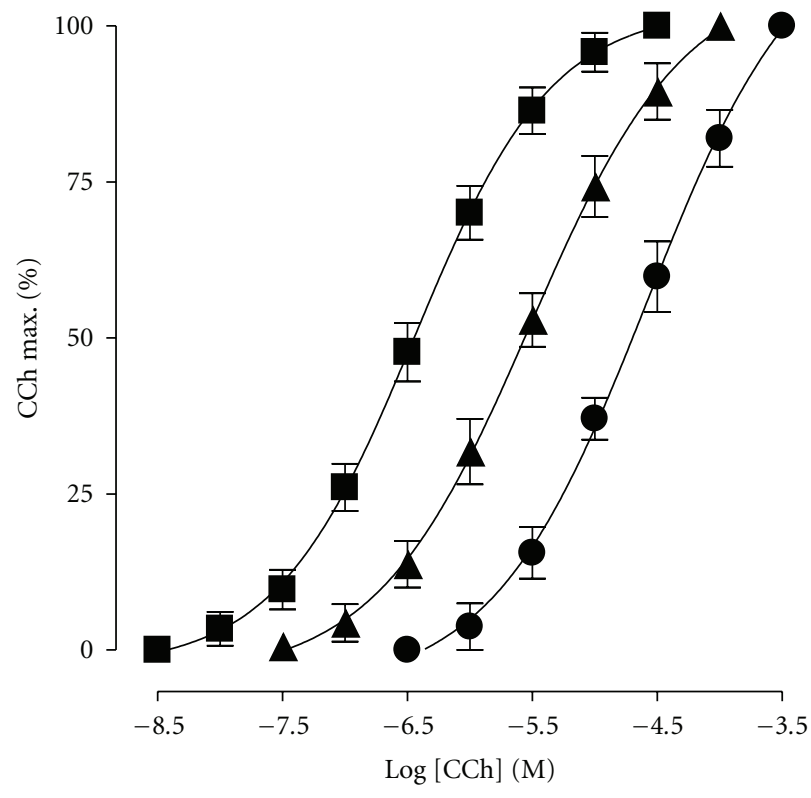

Control

A Atropine $(0.01 \mu \mathrm{M})$

Atropine $(0.03 \mu \mathrm{M})$

(d)

FIGURE 2: Concentration-response curves of carbachol (CCh) in the absence and presence of different concentrations of (a) crude extract of Lepidium sativum (Ls.Cr), (b) dicyclomine, (c) verapamil, and (d) atropine in isolated guinea-pig tracheal preparations, $n=3-4$. 


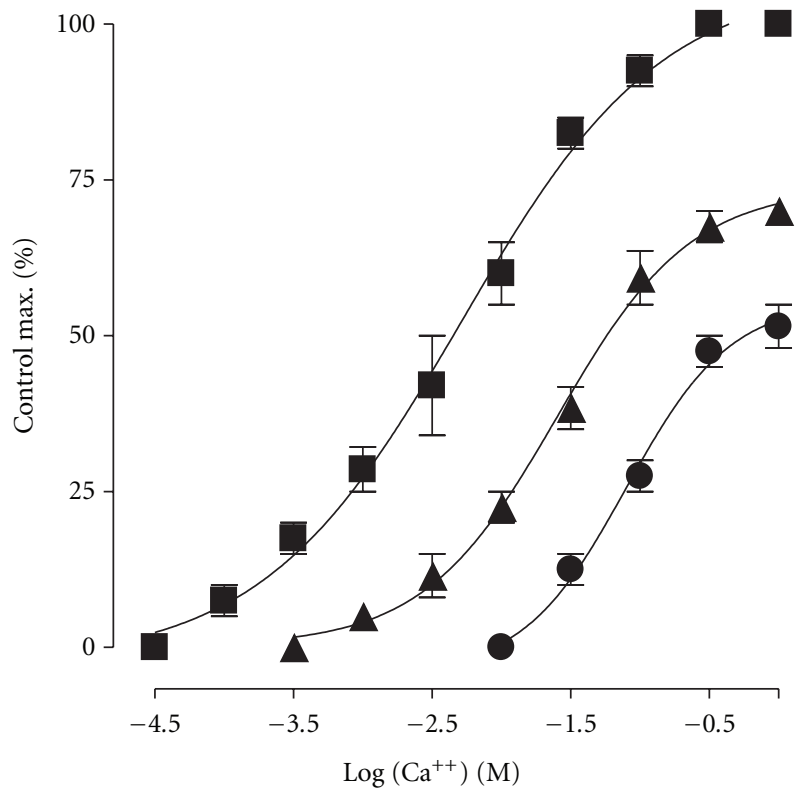

Control

- Ls.Cr $(0.1 \mathrm{mg} / \mathrm{mL})$

Ls.Cr $(0.3 \mathrm{mg} / \mathrm{mL})$

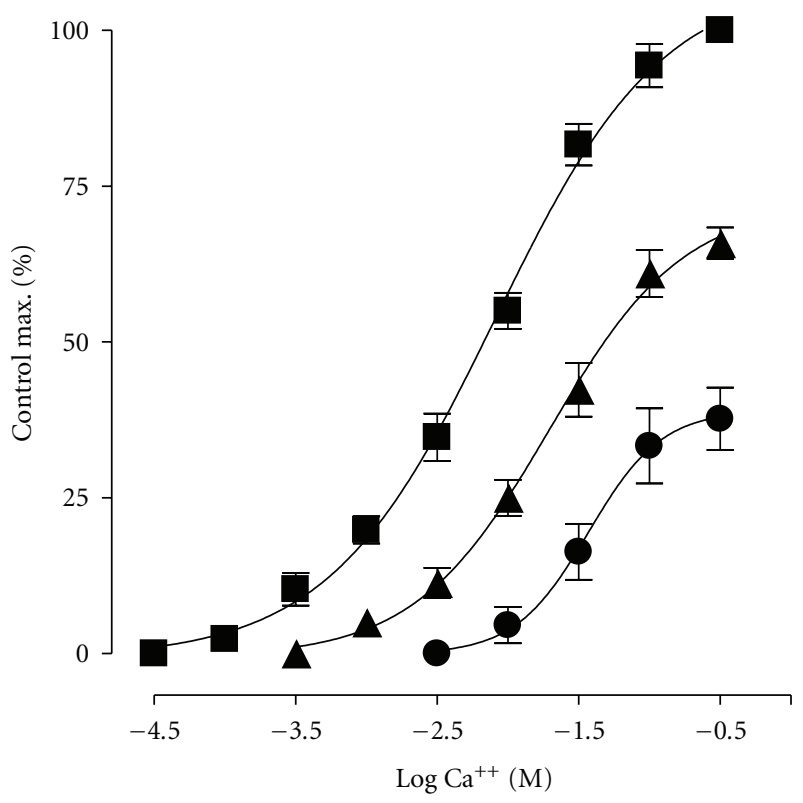

Control

- Verapamil $(0.01 \mu \mathrm{M})$

Verapamil $(0.03 \mu \mathrm{M})$

(a)

(b)

FIgURE 3: Concentration-response curves of $\mathrm{Ca}^{++}$in the absence and presence of the increasing concentrations of (a) crude extract of Lepidium sativum (Ls.Cr) and (b) verapamil in isolated guinea-pig tracheal preparations, $n=3-4$.

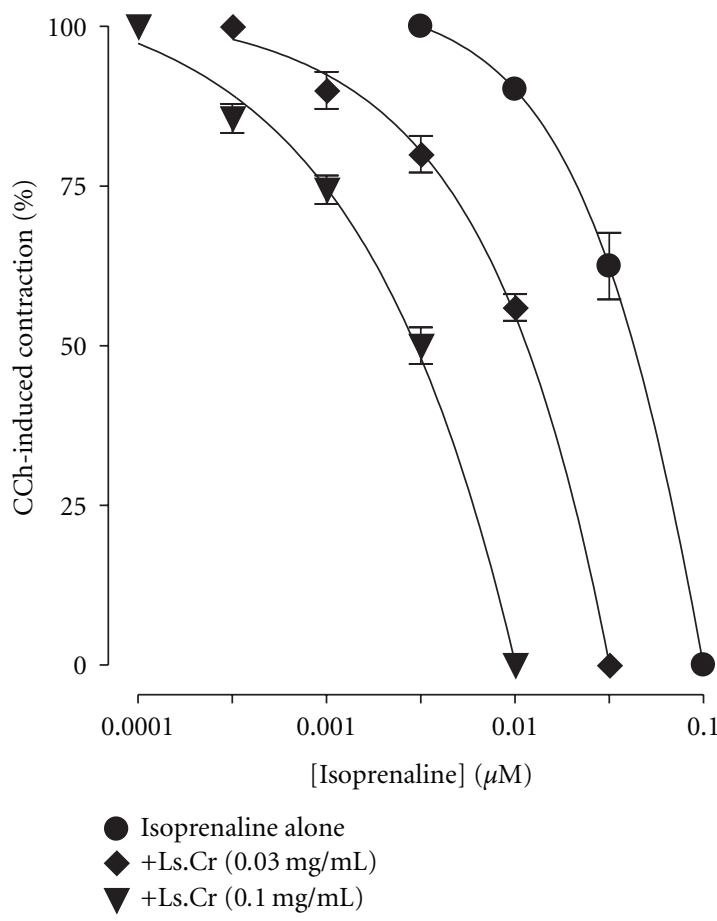

(a)

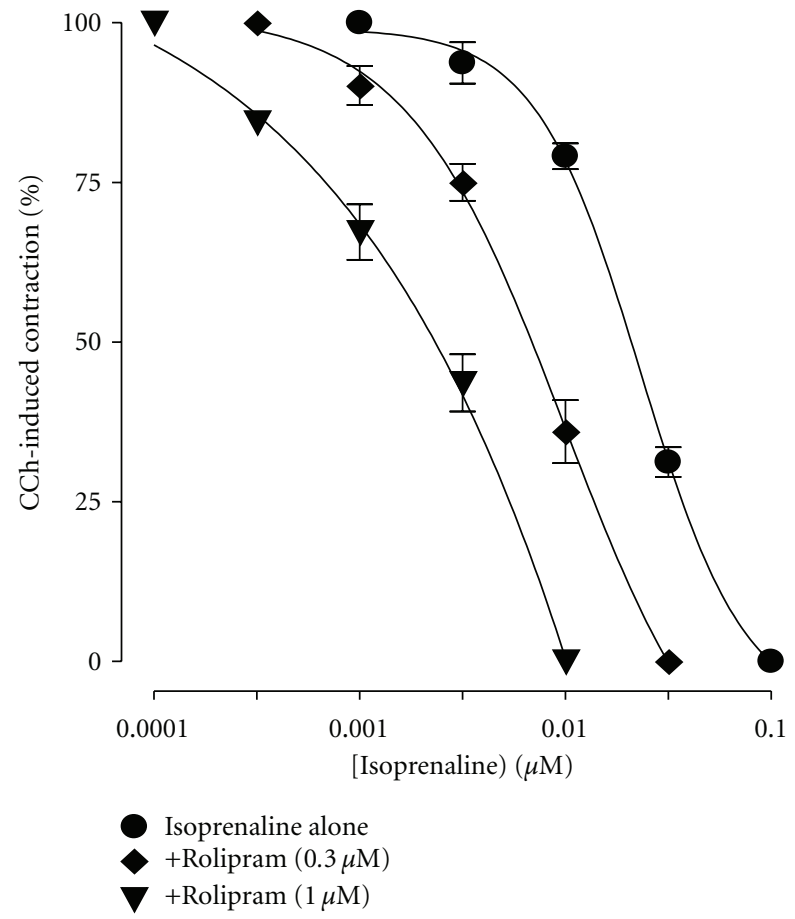

(b)

FIGURE 4: Inhibitory concentration-response curves of isoprenaline against carbachol (CCh)-induced contractions in the absence and presence of different concentrations of (a) crude extract of Lepidium sativum (Ls.Cr) and (b) rolipram in isolated guinea-pig tracheal preparations, $n=3$. The curves obtained by pretreatment of tissues with Ls.Cr and rolipram are significantly different from the respective isoprenaline control curves $(P<0.05)$, Student's $t$-test. 


\section{Discussion}

In view of the medicinal use of Lepidium sativum in the hyperactive airways disorders, its aqueous-methanol extract was tested for the possible bronchodilatory effect. In guineapig tracheal preparations, plant extract inhibited the CChand high $\mathrm{K}^{+}$-induced contractions, being more potent against CCh. Dicylomine, a dual blocker of muscarinic receptors and $\mathrm{Ca}^{++}$influx [31], showed a similar pattern of inhibition, while verapamil, a standard $\mathrm{Ca}^{++}$antagonist [32], was more potent against the $\mathrm{K}^{+}$-induced contractions than those induced by $\mathrm{CCh}$, while atropine, a muscarinic receptor antagonist [33], relaxed the CCh-induced contractions only. It is thereby suggesting the inhibitory effect on muscarinic receptor and $\mathrm{Ca}^{++}$channels. The presence of anticholinergic and $\mathrm{CCB}$ actions was further confirmed, respectively, through constructing the $\mathrm{CCh}$ and $\mathrm{Ca}^{++} \mathrm{CRCs}$ in the presence of different concentrations of the plant extract. A parallel displacement of CCh curves without suppression of the maximum effect was observed at the lower concentration of Ls.Cr, a characteristic of a competitive or specific antagonist, like atropine [34], followed by nonparallel shift with suppression of the maximum effect at higher concentration, pointing towards the presence of nonspecific inhibition, like known with $\mathrm{Ca}^{++}$antagonists [35]. Dicyclomine also shifted the CCh curves to the right, similar to that of the crude extract, while verapamil resulted in rightward but non-parallel shift with suppression of the maximum effect at both the concentrations used. Atropine caused a rightward parallel shift of the CCh curves without suppression of maximum response. Pretreatment of tissues with Ls.Cr shifted the $\mathrm{Ca}^{++}$curves to the right accompanied by the suppression of maximum response, similar to that caused by verapamil, confirming the $\mathrm{Ca}^{++}$antagonistic effect.

We have experienced that plants with medicinal use in the overactive airways disorders usually possess PDE inhibitory effect, which usually coexists with $\mathrm{Ca}^{++}$antagonist activity $[30,36,37]$. To investigate whether Lepidium sativum also exhibits PDE enzyme inhibition component(s), isoprenaline inhibitory CRCs were constructed against CCh-induced contractions by pretreatment of tissues with Ls.Cr, as PDE inhibitors are known to potentiate the isoprenaline effect [38]. The presence of PDE inhibitory effect in Lepidium sativum was confirmed when the plant extract potentiated isoprenaline relaxant effect, by causing leftward shift of isoprenaline-induced inhibitory curves, similar to that caused by rolipram, a $\mathrm{PDE}_{4}$ inhibitor, predominant enzyme in airways [39]. These findings indicate that bronchodilator effect of Lepidium sativum is mediated through combined anticholinergic, CCB, and PDE inhibitory pathways; thus, this study provides sound mechanistic basis for its application in airways hyperactivity disorders. The usefulness of anticholinergics and PDE inhibitors in asthma is well established [40], though major limitation is cardiac stimulation, as a side-effect when applied orally [41, 42]. Interestingly, $\mathrm{Ca}^{++}$antagonists are also useful in bronchoconstriction [43] and are known to exhibit cardiosuppressant effect [44]. The coexistence of CCB constituent(s) with antimuscarinic and PDE inhibitors in Lepidium sativum is perhaps meant by nature to offset the tachycardia, usually associated with anticholinergics or PDE inhibitors when used alone. This scenario strengthens the concept that natural remedies possess "effect enhancing and/or side-effects neutralizing" potential in addition to cost-effectiveness and offers merit in evidence-based studies $[6,45]$.

In conclusion, these results show that Lepidium sativum offers a unique combination of bronchodilator activities (anticholinergic, $\mathrm{Ca}^{++}$antagonist and PDE inhibitory effects), which may explain its medicinal use in the hyperactive airways disorders, such as cough and asthma. However, further in-depth studies are required to probe nature of chemicals constituents and molecular base of biological activities.

\section{Acknowledgments}

This study was initiated during the visit of A. H. Gilani to King Saud University as a part of Visiting Professor Program and partially supported by the Higher Education Commission, Government of Pakistan, as an indigenous Ph.D. scholarship to Mr. Najeeb-ur-Rehman. The authors would express their appreciation to the Deanship of Scientific Research at King Saud University for the provision of funding for publication through the College of Pharmacy Research Center.

\section{References}

[1] S. Malhotra, "Managing asthma in children-the valair study," Pakistan Journal of Chest Medicine, vol. 6, pp. 27-30, 2000.

[2] R. S. Irwin and J. M. Madison, "The diagnosis and treatment of cough," New England Journal of Medicine, vol. 343, no. 23, pp. 1715-1721, 2000.

[3] B. Saad, H. Azaizeh, and O. Said, "Tradition and perspectives of Arab herbal medicine: a review," Evidence-based Complementary and Alternative Medicine, vol. 2, no. 4, pp. 475-479, 2005.

[4] H. Azaizeh, B. Saad, E. Cooper, and O. Said, "Traditional Arabic and Islamic medicine, a re-emerging health aid," Evidence-based Complementary and Alternative Medicine, vol. 7, no. 4, pp. 419-424, 2010.

[5] H. Azaizeh, B. Saad, K. Khalil, and O. Said, "The state of the art of traditional Arab herbal medicine in the Eastern region of the Mediterranean: a review," Evidence-based Complementary and Alternative Medicine, vol. 3, no. 2, pp. 229-235, 2006.

[6] A. H. Gilani and Atta-ur-Rahman, "Trends in ethnopharmacology," Journal of Ethnopharmacology, vol. 100, no. 1-2, pp. 43-49, 2005.

[7] A. M. Ageel, M. Tariq, J. S. Mossa, M. A. Al-Yahya, and M. S. Al-Said, Plant Used in Saudi Folk Medicine: Experimental Report Submitted to the King Abdul Aziz City for Science and Technology, King Saud University Press, Riyadh, Saudi Arabia, 1987.

[8] M. A. Rahman, J. S. Mossa, M. S. Al-Said, and M. A. Al-Yahya, "Medicinal plant diversity in the flora of Saudi Arabia 1: a report on seven plant families," Fitoterapia, vol. 75, no. 2, pp. 149-161, 2004.

[9] H. Kloos, "Preliminary studies of medicinal plants and plant products in Ethiopian markets," Journal of Ethiopian Pharmaceutical Association, vol. 2, pp. 18-28, 1976. 
[10] K. M. Nadkarni, Indian Materia Medica, Popular Prakashan, Bombay, India, 1976.

[11] S. R. Baquar, Medicinal and Poisonous Plants of Pakistan, Printas, Karachi, Pakistan, 1989.

[12] J. A. Duke, M. J. Bogenschutz-Godwin, J. Ducelliar, and P. A. K. Duke, Handbook of Medicinal Herbs, CRC Press, Boca Raton, Fla, USA, 2002.

[13] U. H. Maier, H. Gundlach, and M. H. Zenk, "Seven imidazole alkaloids from Lepidium sativum," Phytochemistry, vol. 49, no. 6, pp. 1791-1795, 1998.

[14] J. A. Duke, Handbook of Phytochemical Constituents of GRAS Herbs and Other Economical Plants, CRC Press, London, UK, 1992.

[15] O. E. Schultz and R. Gmelin, "Purification of glycoside from Lepidum sativum by chromatography on a cellulose powder column," Arzneimittel-Forschung, vol. 2, no. 12, pp. 568-569, 1952.

[16] M. Maghrani, N. A. Zeggwagh, J. B. Michel, and M. Eddouks, "Antihypertensive effect of Lepidium sativum L. in spontaneously hypertensive rats," Journal of Ethnopharmacology, vol. 100, no. 1-2, pp. 193-197, 2005.

[17] U. Patel, M. Kulkarni, V. Undale, and A. Bhosale, "Evaluation of diuretic activity of aqueous and methanol extracts of Lepidium sativum garden cress (Cruciferae) in rats," Tropical Journal of Pharmaceutical Research, vol. 8, no. 3, pp. 215-219, 2009.

[18] M. A. Al-Yahya, J. S. Mossa, A. M. Ageel, and S. Rafatullah, "Pharmacological and safety evaluation studies on Lepidium sativum L. seeds," Phytomedicine, vol. 1, pp. 155-159, 1994.

[19] S. K. Ahsan, M. Tariq, M. Ageel, M. A. Al-Yahya, and A. H. Shah, "Studies on some herbal drugs used in fracture healing," International Journal of Crude Drug Research, vol. 27, no. 4, pp. 235-239, 1989.

[20] A. P. Patole, "Effect of mucilaginous seeds on in vitro rate of starch hydrolysis and blood glucose levels of NIDDM subjects with special reference to garden cress seeds," Journal of Medicinal and Aromatic Plant Sciences, vol. 20, pp. 1005-1008, 1998.

[21] N. Rehman, M. H. Mehmood, K. M. Alkharfy, and A. H. Gilani, "Prokinetic and laxative activities of Lepidium sativum seed extract with species and tissue selective gut stimulatory actions," Journal of Ethnopharmacology, vol. 134, pp. 878-883, 2011.

[22] N. Rehman, M. H. Mehmood, K. M. Alkharfy, and A. H. Gilani, "Studies on antidiarrhoel and antispasmodic activities of Lepidium sativum crude extract in rats," Phytotherapy Research. In press.

[23] A. N. Paranjape and A. A. Mehta, "A study on clinical efficacy of Lepidium sativum seeds in treatment of bronchial asthma," Iranian Journal of Pharmacology and Therapeutics, vol. 5, no. 1, pp. 55-59, 2006.

[24] R. G. Mali, S. G. Mahajan, and A. A. Mehta, "Studies on bronchodilatory effect of Lepidium sativum against allergen induced bronchospasm in guinea pigs," Pharmacognosy Magazine, vol. 4, no. 15, pp. 189-192, 2008.

[25] M. Kaur and R. K. Goel, "Anti-convulsant activity of Boerhaavia diffusa: plausible role of calcium channel antagonism," Evidence-Based Complementary and Alternative Medicine, vol. 2011, Article ID 310420, 7 pages, 2011.

[26] National Research Council, Guide for the Care and Use of Laboratory Animals, National Academy Press, Washington, DC, USA, 1996.
[27] T. Godfraind, R. Miller, and M. Wibo, "Calcium antagonism and calcium entry blockade," Pharmacological Reviews, vol. 38, no. 4, pp. 321-416, 1986.

[28] S. Bashir, R. Memon, and A. H. Gilani, "Antispasmodic and antidiarrheal activities of Valeriana hardwickii rhizome are putatively mediated through calcium channel blockade," Evidence-Based Complementary and Alternative Medicine, vol. 2011, Article ID 304960, 6 pages, 2011.

[29] A. J. Shah and A. H. Gilani, "Bronchodilatory effect of Acorus calamus (Linn.) is mediated through multiple pathways," Journal of Ethnopharmacology, vol. 131, no. 2, pp. 471-477, 2010.

[30] A. H. Gilani, A. U. Khan, F. Subhan, and M. Khan, "Antispasmodic and bronchodilator activities of St John's wort are putatively mediated through dual inhibition of calcium influx and phosphodiesterase," Fundamental and Clinical Pharmacology, vol. 19, no. 6, pp. 695-705, 2005.

[31] J. W. Downie, D. A. S. Twiddy, and S. A. Awad, "Antimuscarinic and noncompetitive antagonist properties of dicyclomine hydrochloride in isolated human and rabbit bladder muscle," Journal of Pharmacology and Experimental Therapeutics, vol. 201, no. 3, pp. 662-668, 1977.

[32] A. Fleckenstein, "Specific pharmacology of $\mathrm{Ca}^{++}$in myocardium, cardiac pacemakers, and vascular smooth muscle," Annual Review of Pharmacology and Toxicology, vol. 17, pp. 149-166, 1977.

[33] R. E. Delmendo, A. D. Michel, and R. L. Whiting, "Affinity of muscarinic receptor antagonists for three putative muscarinic receptor binding sites," British Journal of Pharmacology, vol. 96, no. 2, pp. 457-464, 1989.

[34] O. Arunlakhshana and H. O. Schild, "Some quantitative uses of drug antagonists," British Journal of Pharmacology and Chemotherapy, vol. 14, no. 1, pp. 48-58, 1959.

[35] A. H. Gilani, A. U. Khan, T. Ali, and S. Ajmal, "Mechanisms underlying the antispasmodic and bronchodilatory properties of Terminalia bellerica fruit," Journal of Ethnopharmacology, vol. 116, no. 3, pp. 528-538, 2008.

[36] A. H. Gilani, A. J. Shah, A. Zubair et al., "Chemical composition and mechanisms underlying the spasmolytic and bronchodilatory properties of the essential oil of Nepeta cataria L," Journal of Ethnopharmacology, vol. 121, no. 3, pp. 405-411, 2009.

[37] M. Khan, A. Khan, N. Rehman, and A. H. Gilani, "Pharmacological explanation for the use of Juniperus excelsa in hyperactive gastrointestinal and respiratory disorders," Journal of Natural Medicines. In press.

[38] K. L. Lorenz and J. N. Wells, "Potentiation of the effects of sodium nitroprusside and of isoproterenol by selective phosphodiesterase inhibitors," Molecular Pharmacology, vol. 23, no. 2, pp. 424-430, 1983.

[39] B. J. Lipworth, "Phosphodiesterase-4 inhibitors for asthma and chronic obstructive pulmonary disease," The Lancet, vol. 365, no. 9454, pp. 167-175, 2005.

[40] P. J. Barnes, "Drugs for asthma," British Journal of Pharmacology, vol. 147, supplement 1, pp. S297-S303, 2006.

[41] J. G. Nicholas, "Anticholinergic agents in asthma and COPD," European Journal of Pharmacology, vol. 533, no. 1-3, pp. 3639, 2006.

[42] H. Nawrath, "Action potential, membrane currents and force of contraction in cat ventricular heart muscle treated with papaverine," Journal of Pharmacology and Experimental Therapeutics, vol. 218, no. 2, pp. 544-549, 1981.

[43] M. A. Twiss, E. Harman, S. Chesrown, and L. Hendeles, "Efficacy of calcium channel blockers as maintenance therapy for 
asthma," British Journal of Clinical Pharmacology, vol. 53, no. 3, pp. 243-249, 2002.

[44] G. E. Billman, "The antiarrythmic effects of the calcium antagonists," in Calcium Antagonists in Clinical Medicine, M. Epstein, Ed., pp. 183-212, Hanley and Belfus, Philadelphia, Pa, USA, 1992.

[45] E. Ernst, "The efficacy of herbal medicine-an overview," Fundamental and Clinical Pharmacology, vol. 19, no. 4, pp. 405409, 2005. 


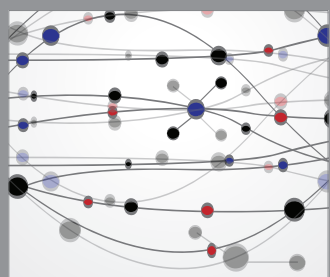

The Scientific World Journal
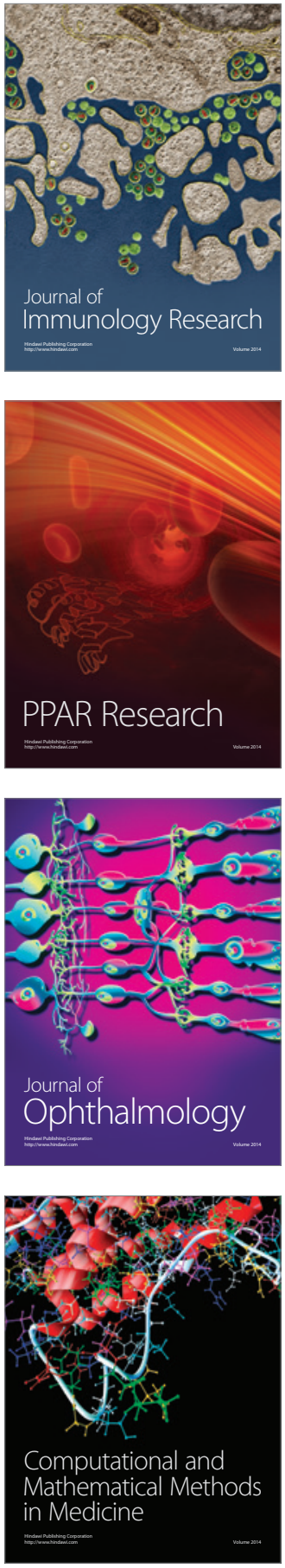

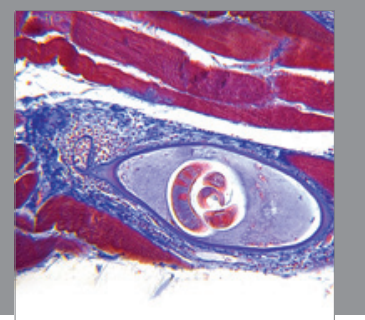

Gastroenterology

Research and Practice
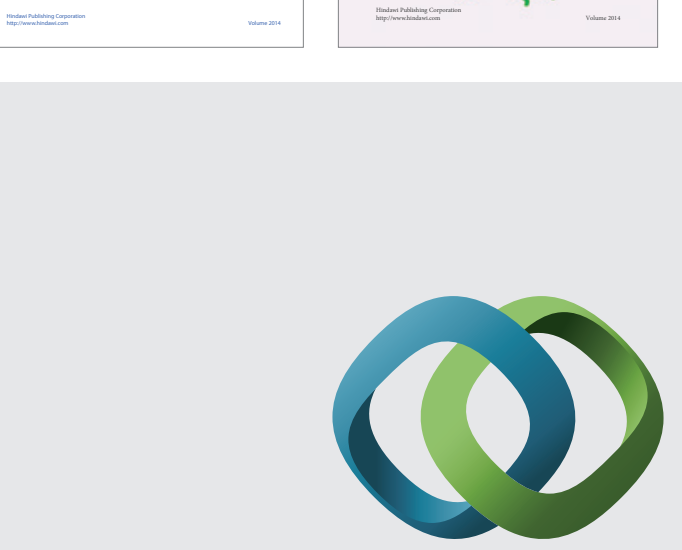

\section{Hindawi}

Submit your manuscripts at

http://www.hindawi.com
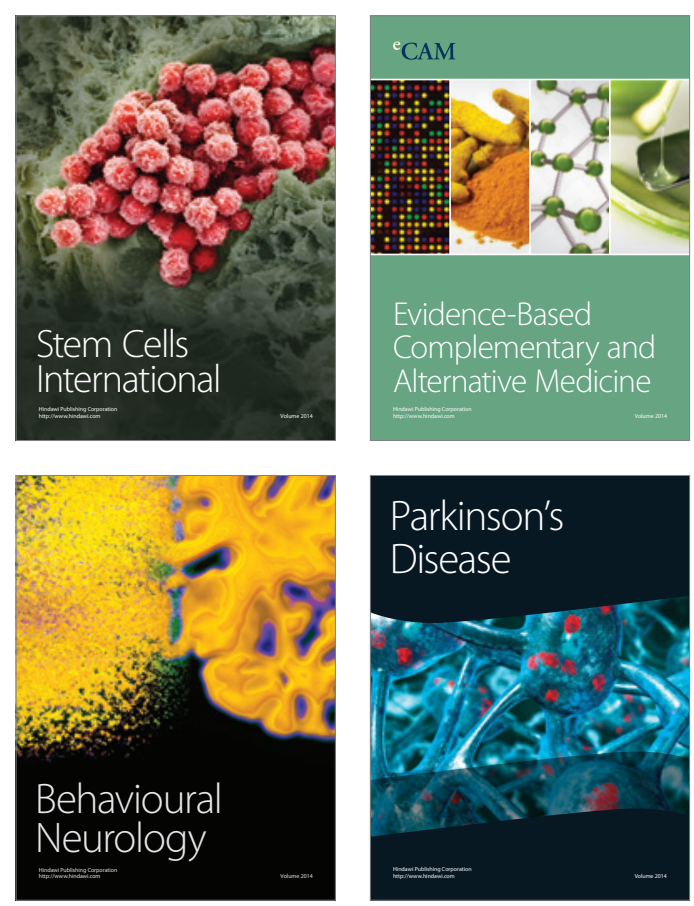

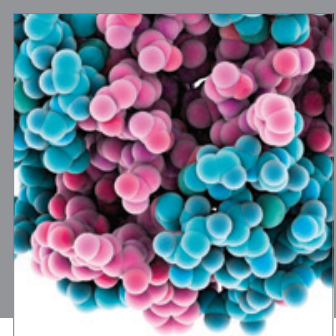

Journal of
Diabetes Research

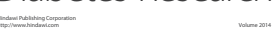

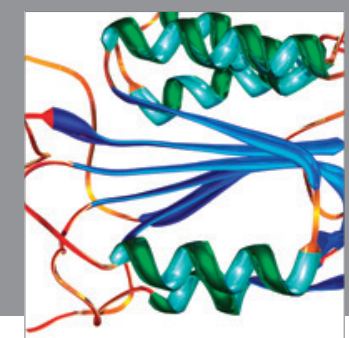

Disease Markers
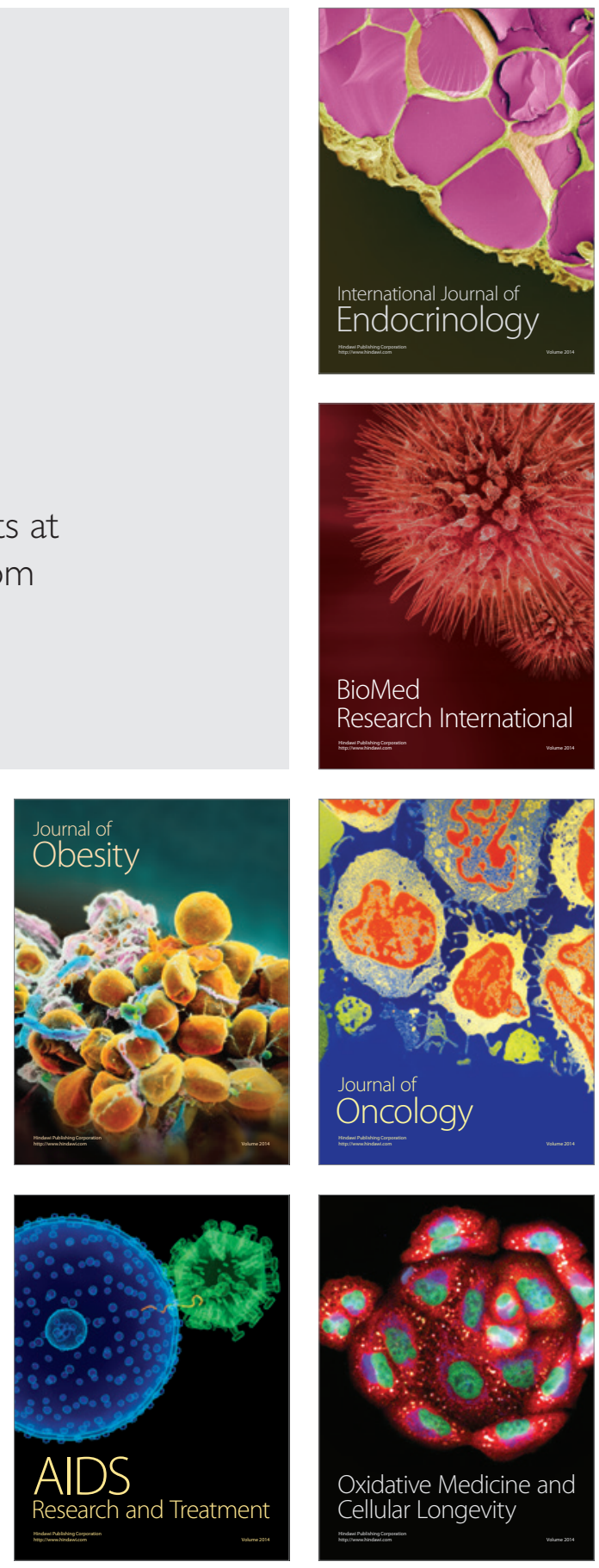